\title{
Three infection clusters related with potential pre- symptomatic transmission of coronavirus disease (COVID-19), Shanghai, China, January to February 2020
}

Xiaohuan Gong ${ }^{1,2}$, Wenjia Xiao $0^{1,2}$, Yan Cui ${ }^{2,3}$, Yuanping Wang ${ }^{2,4}$, Dechuan Kong ${ }^{1}$, Shenghua Mao ${ }^{1}$, Yaxu Zheng ${ }^{1}$, Lunhui Xiang $^{5}$,

Lu Lu ${ }^{6}$, Chenyan Jiang ${ }^{1}$, Xiao Yu ${ }^{1}$, Yiyi Zhu ${ }^{1}$, Qiwen Fang ${ }^{1}$, Hao Pan ${ }^{7}$, Huanyu Wu ${ }^{1}$

1. Department of Infectious Disease Control and Prevention, Shanghai Municipal Center for Disease Control and Prevention, Shanghai, China

2. These authors contributed equally to this work

3. Putuo District Center for Disease Control and Prevention, Shanghai, China

4. Pudong District Center for Disease Control and Prevention, Shanghai, China

5. Baoshan District Center for Disease Control and Prevention, Shanghai, China

6. Huangpu District Center for Disease Control and Prevention, Shanghai, China

7. Shanghai Institutes of Preventive Medicine, Shanghai, China

Correspondence: Huanyu Wu (wuhuanyu_scdc@126.com), Hao Pan (panhao_scdc@126.com)

Citation style for this article:

Gong Xiaohuan, Xiao Wenjia, Cui Yan, Wang Yuanping, Kong Dechuan, Mao Shenghua, Zheng Yaxu, Xiang Lunhui , Lu Lu , Jiang Chenyan, Yu Xiao, Zhu Yiyi , Fang Qiwen, Pan Hao, Wu Huanyu. Three infection clusters related with potential pre-symptomatic transmission of coronavirus disease (COVID-19), Shanghai, China, January to February 2020. Euro Surveill. 2020;25(33):pii=2000228. https://doi.org/10.2807/1560-7917.ES.2020.25.33.2000228

We report three clusters related with potential presymptomatic transmission of coronavirus disease (COVID-19) between January and February 2020 in Shanghai, China. Investigators interviewed suspected COVID-19 cases to collect epidemiological information, including demographic characteristics, illness onset, hospital visits, close contacts, activities' trajectories between 14 days before illness onset and isolation, and exposure histories. Respiratory specimens of suspected cases were collected and tested for SARSCoV-2 by real-time reverse-transcriptase polymerase chain reaction ( $R$ RT-PCR) assay. The interval between the onset of illness in the primary case and the last contact of the secondary case with the primary case in our report was 1 to 7 days. In Cluster 1 (five cases), illness onset in the five secondary cases was 2 to 5 days after the last contact with the primary case. In Cluster 2 (five cases) and Cluster 3 (four cases), the illness onset in secondary cases occurred prior to or on the same day as the onset in the primary cases. The study provides empirical evidence for transmission of COVID-19 during the incubation period and indicates that pre-symptomatic person-to-person transmission can occur following sufficient exposure to confirmed COVID-19 cases. The potential pre-symptomatic person-to-person transmission puts forward higher requirements for prevention and control measures.

\section{Background}

An outbreak of pneumonia of unknown aetiology occurred in Wuhan, Hubei Province, China, in December
$2019[1,2]$. The first cases were linked to exposure at Wuhan's Huanan Seafood Wholesale Market. A novel coronavirus, severe acute respiratory syndrome coronavirus 2 (SARS-CoV-2), was identified as the causing infectious agent [3] and the World Health Organization (WHO) declared a public health emergency of international concern on 30 January and a pandemic on 11 March $2020[4,5]$. As at 29 March 2020, there were 82,356 coronavirus disease 2019 (COVID-19) confirmed cases in China and 634,813 confirmed cases globally [6]. The COVID-19 pandemic has since continued to progress rapidly worldwide $[7,8]$.

As at 21 January 2020, Hubei Province reported 375 confirmed cases and Shanghai had reported nine confirmed cases [9]. On 24 January, the Shanghai Municipal Government declared the first-level response for a major public health emergency to firmly curb the spread of the epidemic [10]. Stringent prevention and control measures were implemented, including strengthening health screening and quarantine, cancelling various large-scale public activities, encouraging people to stay at home and to wear a mask in unavoidable outside activities.

There was early evidence for human-to-human transmission among close contacts, such as in hospital, family and community settings [11-14]. Although evidence of pre-symptomatic transmission accumulated [15-17], the infectivity and duration of transmission during the incubation period have been inconclusive. 
Timeline of exposure to pre-symptomatic case and illness onsets of cases in Cluster 1 of COVID-19 outbreak, Shanghai, China, 12 January-1 February $2020(\mathrm{n}=5)$

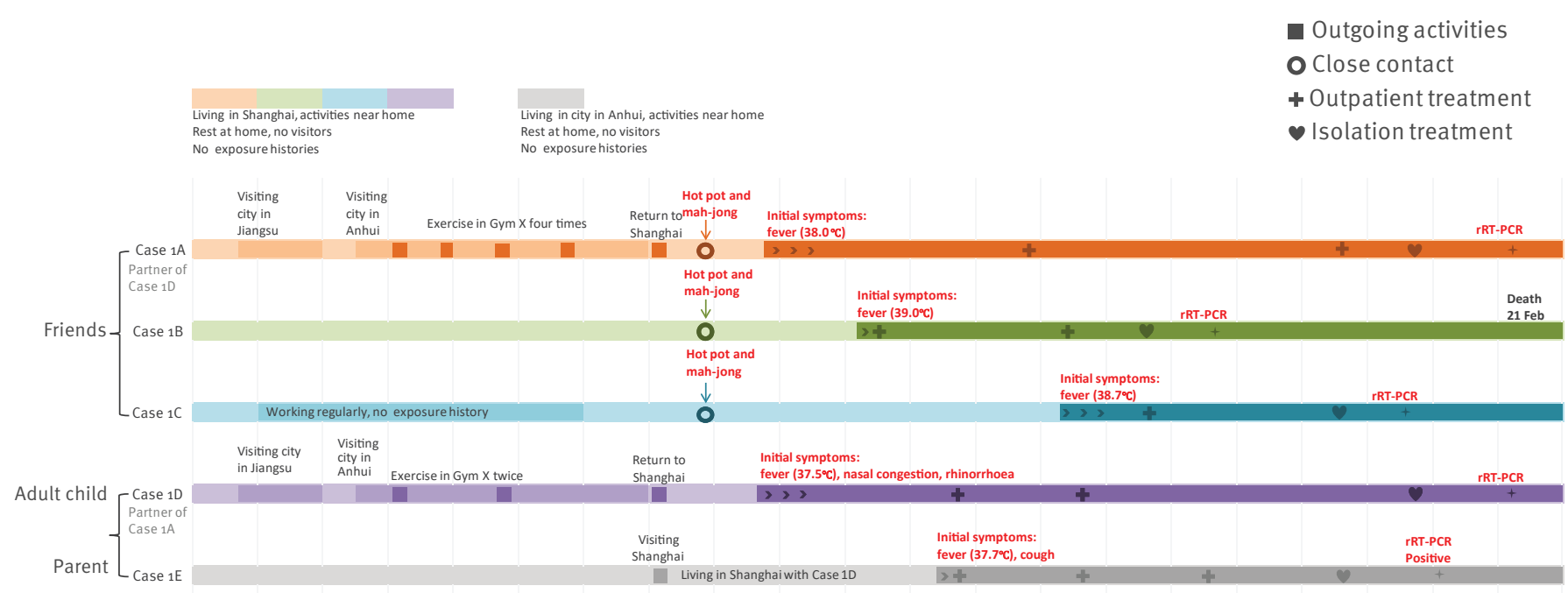

These key epidemiological parameters, however, are important for outbreak control and to reduce virus transmission. Virus spread by pre-symptomatic cases poses great challenges to disease control and has an important impact on preventive strategies.

\section{Outbreak detection}

Between 26 and 30 January 2020, three hospitals in two districts of Shanghai city reported five suspected COVID-19 cases to the local district Centers for Disease Control and Prevention (CDC). The five cases (Cluster 1) were laboratory-confirmed 1-2 days later by the Shanghai municipal CDC laboratory; two were index cases and three were close contacts, i.e. friends and close family members. Cases had histories of common activities, such as travelling and dining, or were living together.

On 1 February 2020, another hospital in Shanghai reported one suspected COVID-19 case and six of their close contacts to the local district CDC; four of the close contacts tested positive for SARS-CoV-2 by realtime reverse-transcriptase polymerase chain-reaction (rRT-PCR), 1-2 days later (Cluster 2). The seven persons were from one family, including four grandparents plus a young couple and their infant. Two grandparents had come to Shanghai from Wuhan on 21 January.

From 21-23 January 2020, a further hospital in Shanghai reported four suspected COVID-19 cases to the local district CDC. These four cases (Cluster 3), two index cases and two close contacts, were laboratoryconfirmed 1 day later. They were from two couples and two of the four individuals were siblings. One couple had come to Shanghai from Wuhan on 15 January and had lived with the other couple since then.
Initial investigations revealed the epidemiological links in each of these thee clusters. Further epidemiological investigations, control measures and specimen collection were conducted by a joint field epidemiology team from the respective days when reports were received. We report the key findings of the field epidemiological investigations of the three infection clusters related with potential pre-symptomatic transmission of COVID-19.

\section{Methods}

\section{Epidemiological investigation}

A joint field epidemiology team, comprising public health physicians from Shanghai municipal CDC and local district CDCs, was formed and conducted detailed field investigations from the day COVID-19 case reports were received. Investigators interviewed COVID-19 cases, close contacts and healthcare workers directly (face-to-face or over the phone) to collect epidemiological information including demographic characteristics, date of illness onset, hospital visits, close contacts, activities' trajectories between 14 days before illness onset and isolation and exposure histories (i.e. travel to or living in Wuhan or Hubei Province, visiting any other area with local sustained transmission of SARSCoV-2, contact with persons with respiratory symptoms, contact with suspected or confirmed COVID-19 cases). In addition to interviews, medical records and travel records were checked, security cameras' videos were retrieved, and on-site investigation of key public settings were performed. The epidemiological information of cases from multiple sources was cross-checked to ensure the reliability of information. Once an infection cluster was identified, epidemiological links and transmission chains were analysed. 
Timeline of exposure to pre-symptomatic case and illness onsets of cases in Cluster 2 of COVID-19 outbreak, Shanghai, China, 15 January-4 February $2020(\mathrm{n}=5)$

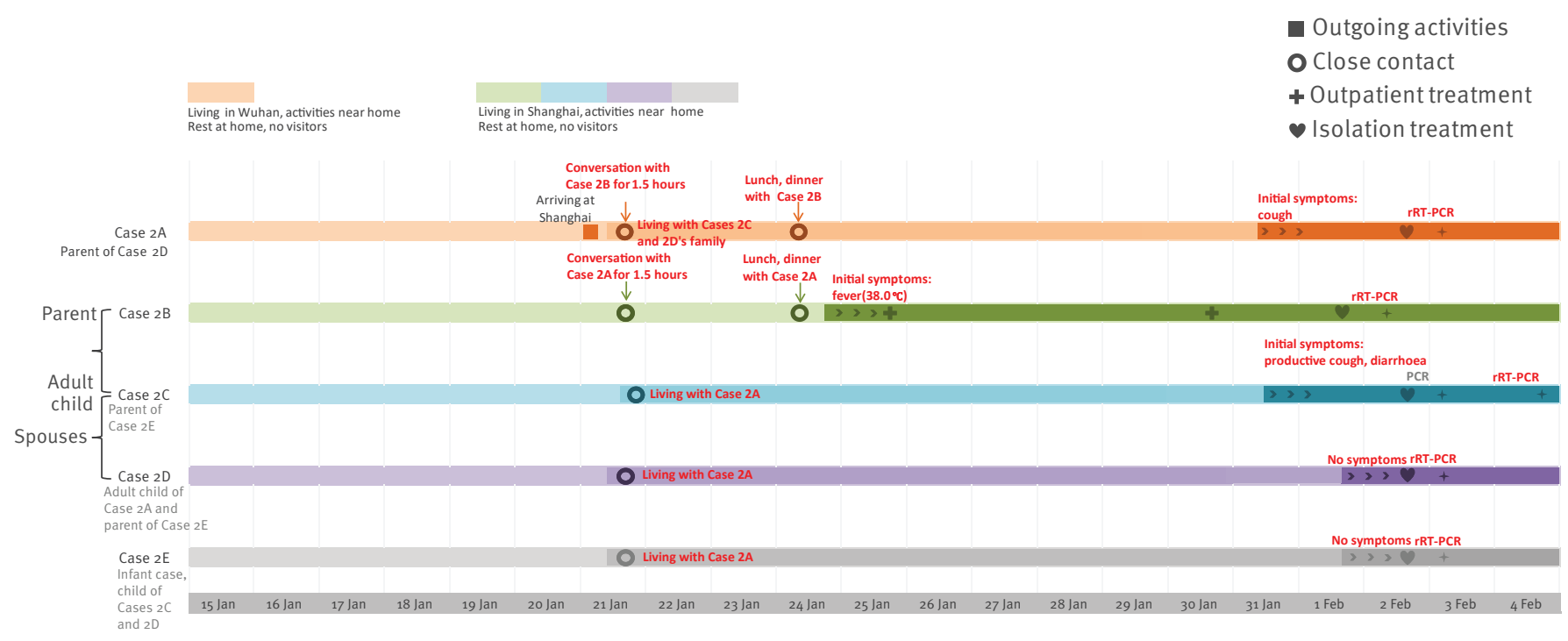

\section{Laboratory detection}

Upper respiratory specimens (nasopharyngeal swab, throat swab and/or nasopharyngeal-throat swab) and/ or lower respiratory specimens (sputum) of suspected cases were collected and tested for SARS-CoV-2 by rRT-PCR assay in the Shanghai municipal CDC laboratory. The viral target included open reading frame $1 \mathrm{ab}$ (ORF1ab) and nucleocapsid protein $(\mathrm{N})$. The specimen was positive for COVID-19 only if both viral targets were positive $[18,19]$.

\section{Definitions of cases and contacts}

We used the 3 rd version of Prevention and Control Guidelines for Novel Coronavirus Pneumonia by the National Health Commission of the People's Republic of China's case definition [18]. A suspected case was defined as any person meeting clinical signs of COVID19 and/or with epidemiological histories. A confirmed case was any suspected case with respiratory samples testing rRT-PCR-positive for SARS-CoV-2.

Epidemiological histories were defined as (i) history of travelling or residing in Wuhan or any other areas where local sustained transmission of COVID-19 existed within 14 days before illness onset, (ii) history of contact with patients with fever or respiratory symptoms from Wuhan or any other area where local sustained transmission of COVID-19 existed within 14 days before illness onset, and (iii) clustering of illness onsets, or having an epidemiological association with cases rRTPCR-positive for SARS-CoV-2.

Clinical and laboratory signs included were (i) fever, (ii) radiological evidence of pneumonia, (iii) normal or under normal white blood cell count in early stage, or under normal lymphocyte count.

An infection cluster was identified if more than one SARS-CoV-2 rRT-PCR-positive case was found in a confined environment or group (such as a family, a company, etc.) within 14 days, and there was a possibility of interpersonal transmission because of close contact or co-exposure.

A close contact was anyone who was closely in contact with a suspected, confirmed and asymptomatic case without effective personal protection (classified protection according to the contact situation, including gloves, medical protective masks, protective face screens, isolation clothing, etc.) since onset of symptoms in the suspected case and confirmed case or the day asymptomatic case's specimens were collected. The close contact included: (i) living, working, or studying in one house or classroom, (ii) diagnosing, treating, or visiting cases in hospital ward, (iii) being within short distance in the same vehicle, (iv) other situations assessed by the field investigators.

\section{Ethical statement}

The epidemiological investigations were carried out according to the Law of the People's Republic of China on prevention and control of infectious diseases [20]. Ethical approval was not required because the CDCs are able to access and use personal identifiable information for infectious disease outbreak investigation according to the Law of the People's Republic of China on prevention and control of infectious diseases [20]. All cases were informed about the related rights and obligations and oral consent was obtained from all cases. Details were anonymised to protect the individual's privacy. 
Timeline of exposure to pre-symptomatic case and illness onsets of cases in Cluster 3 of COVID-19 outbreak, Shanghai, China, 6 January-25 January $2020(\mathrm{n}=4)$

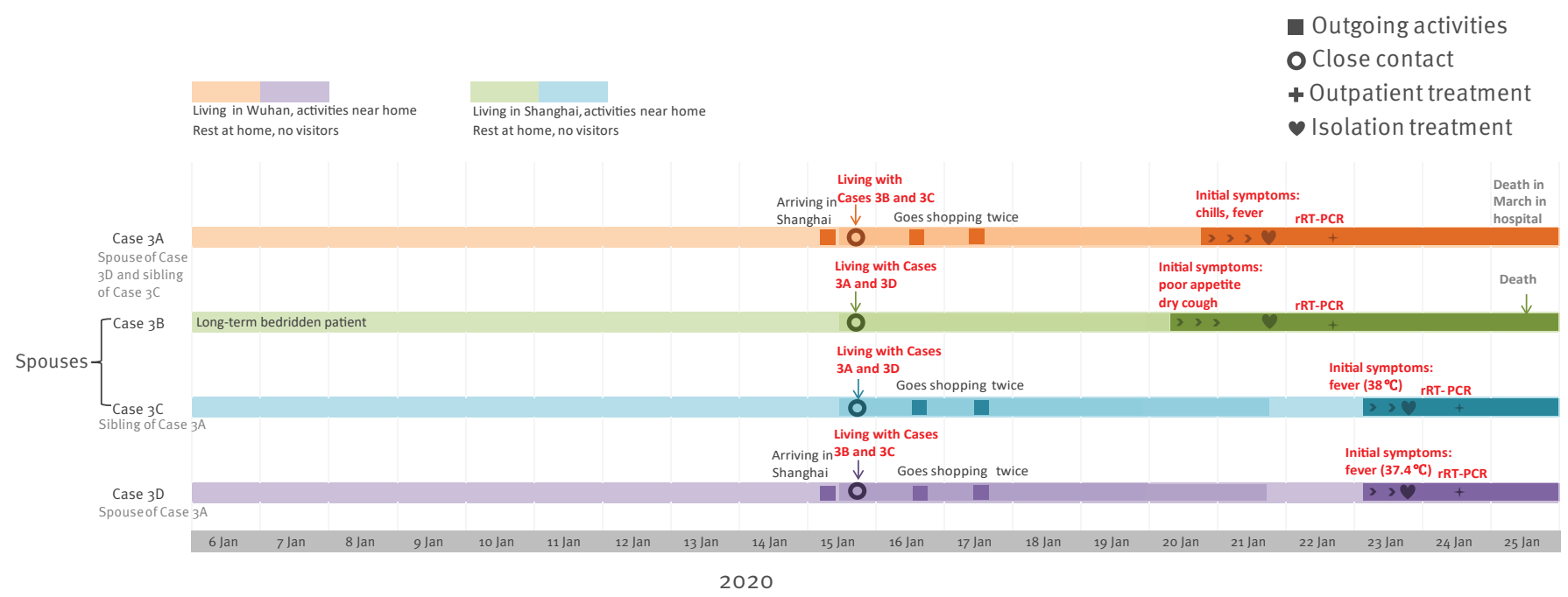

\section{Results}

\section{Description of clusters}

\section{Cluster 1}

Cluster 1 involved five confirmed COVID-19 cases; three females and two males. Cases $1 \mathrm{~A}$ to $1 \mathrm{C}$, two males and one female, all in their 20s, were friends. Case $1 D$ also in their 205 was the partner of Case $1 \mathrm{~A}$ whereas Case $1 \mathrm{E}$, who was in their 50 , was parent of Case $1 \mathrm{D}$.

Cases $1 \mathrm{~A}$ to $1 \mathrm{D}$ lived in Shanghai. On 12 January, Case 1D went on duty travel to a city in Jiangsu Province, accompanied by Case $1 \mathrm{~A}$, where Case $1 \mathrm{~A}$ went for a haircut and to a gym for exercise. Two days later, Cases $1 \mathrm{~A}$ and $1 \mathrm{D}$ travelled to a city in Anhui Province, where Case $1 \mathrm{E}$ lived. Here, Cases $1 \mathrm{~A}$ and $1 \mathrm{D}$ participated in a wedding and then a family dinner with relatives. Case $1 \mathrm{~A}$ exercised with Case $1 \mathrm{D}$ twice and exercised alone twice in Gym X. Five days after their arrival, Cases $1 \mathrm{~A}$, $1 \mathrm{D}$ and $1 \mathrm{E}$ returned to Shanghai. Cases $1 \mathrm{~A}$ dined with Cases $1 \mathrm{~B}, 1 \mathrm{C}$ and two friends in a hotpot restaurant between 17:00 and 20:00 on the same day. Then they played mah-jong in a separate room with poor ventilation in the chess and cards parlour, between 20:00 and 23:00. These five people went home separately and had no further contact with each other before illness onset.

Case $1 \mathrm{~A}$ became symptomatic with fever $\left(38.0^{\circ} \mathrm{C}\right)$ at night on 20 January. They presented to hospital accompanied by a parent on 24 January and were diagnosed with bronchitis. The examination showed: body temperature was $38.5^{\circ} \mathrm{C}$, white blood cell count was 6.02 $\times 10^{9} / \mathrm{L}$ (norm 4.0-10.0 X 109/L). Influenza $A$ and B antigen tests were both negative. Case $1 \mathrm{~A}$ visited the hospital again, accompanied by their parent, on 29 January because of persisting symptoms. Chest computed tomography (CT) scan showed scattered patches and increased density in both lungs. They went back home that day. Following Case 1 E's detection as suspected COVID-19 case on 29 January, Case 1A returned to hospital alone and was suspected as COVID-19 case one day later, when they were isolated and treated. The nasopharyngeal-throat swab was rRT-PCR positive for SARS-CoV-2 on 1 February.

Case $1 \mathrm{~B}$ developed fever $\left(39.0^{\circ} \mathrm{C}\right)$ at $02: 00$ on 22 January. They developed headache, productive cough (bloodshot) and myalgia subsequently during 23 and 25 January. They presented to hospital accompanied by their parent on 22 January and 25 January, respectively. Influenza B antigen test was positive and influenza A antigen test was negative. On 26 January, they went to hospital again, accompanied by their parent, were suspected as COVID-19 case, were isolated and received treatment at the hospital. The examination showed: white blood cell count was $4.0 \times 10^{9} / \mathrm{L}$. Chest CT scan showed multiple ground glass opacities in both lungs. The nasopharyngeal-throat swab and sputum specimen were both rRT-PCR positive for SARS-CoV-2 on 27 January. Case $1 \mathrm{~B}$ died in February at the treating hospital.

Case $1 \mathrm{C}$ had a fever $\left(38.7^{\circ} \mathrm{C}\right)$ at $09: 00$ on 25 January. They visited the hospital accompanied by their parent on 26 January, got symptomatic treatment and went back home. As Case 1B's close contact with symptoms, Case ${ }_{1} \mathrm{C}$ visited the hospital again, alone; they were suspected as COVID-19 case, they were isolated and received treatment at hospital on 29 January. The examination showed: body temperature was $37.6^{\circ} \mathrm{C}$, white blood cell count was $3.6 \times 10^{9} / \mathrm{L}$. Chest CT scan showed infection in the left lung. The sputum specimen was rRT-PCR positive for SARS-CoV-2 on 30 January.

Cases $1 \mathrm{D}$ and $1 \mathrm{E}$ became symptomatic on 20 January and 23 January, respectively. Case $1 \mathrm{E}$ was isolated and received treatment on 29 January. As Case 1 E's close contact with symptoms, Case $1 \mathrm{D}$ was isolated and 
Demographic and clinical characteristics of confirmed COVID-19 cases related with potential pre-symptomatic transmission in three infection clusters, Shanghai, China, January-February $2020(\mathrm{n}=8)$

\begin{tabular}{|c|c|c|c|c|c|c|c|c|c|c|c|}
\hline Cluster & Case & $\begin{array}{c}\text { Age } \\
\text { (years) }\end{array}$ & BMI & Smoking & Comorbidity & $\begin{array}{l}\text { Fever } \\
\left({ }^{\circ} \mathrm{C}\right)\end{array}$ & $\begin{array}{l}\text { Other } \\
\text { respiratory } \\
\text { symptoms }\end{array}$ & $\begin{array}{l}\text { Influenza } \\
\text { antigen } \\
\text { test }\end{array}$ & $\begin{array}{l}\text { White blood } \\
\text { cell (x } \\
\text { 109/L, (norm } \\
4.0-10.0 \text { ) }\end{array}$ & $\begin{array}{c}\text { Chest computed } \\
\text { tomography } \\
\text { scan }\end{array}$ & $\begin{array}{l}\text { Clinical } \\
\text { outcome }\end{array}$ \\
\hline \multirow{3}{*}{ Cluster 1} & Case $1 \mathrm{~A}$ & $20-30$ & 30.4 & No & None & $\begin{array}{c}38.0- \\
38.5\end{array}$ & NA & $\begin{array}{l}\text { Influenza } \\
\mathrm{A} \text { and } \mathrm{B} \\
\text { negative }\end{array}$ & $4.1-6.0$ & $\begin{array}{c}\text { Scattered } \\
\text { patches and } \\
\text { increased } \\
\text { density in both } \\
\text { lungs }\end{array}$ & Recovery \\
\hline & Case 1B & $20-30$ & 35.5 & No & None & $\begin{array}{l}37.6- \\
39.0\end{array}$ & $\begin{array}{c}\text { Headache, } \\
\text { productive } \\
\text { cough, } \\
\text { myalgia } \\
\end{array}$ & $\begin{array}{l}\text { Influenza } \\
\text { B positive }\end{array}$ & 4.0 & $\begin{array}{l}\text { Multiple ground } \\
\text { glass opacities } \\
\text { in both lungs }\end{array}$ & Death \\
\hline & Case $1 \mathrm{C}$ & $20-30$ & 22.9 & No & None & $\begin{array}{l}37.3^{-} \\
38.7\end{array}$ & NA & NA & 3.6 & $\begin{array}{c}\text { Infection in left } \\
\text { lung }\end{array}$ & Recovery \\
\hline \multirow{3}{*}{ Cluster 2} & Case $2 \mathrm{~A}$ & $50-60$ & NA & Yes & None & NA & Cough & NA & NA & NA & Recovery \\
\hline & Case 2B & $60-70$ & 22.6 & Yes & $\begin{array}{l}\text { Diabetes } \\
\text { mellitus }\end{array}$ & $\begin{array}{c}37.3^{-} \\
38\end{array}$ & NA & NA & $3.8-4.2$ & $\begin{array}{l}\text { Infectious } \\
\text { lesions of both } \\
\text { lungs and thin } \\
\text { nodular shadow } \\
\text { of left lung }\end{array}$ & Recovery \\
\hline & Case $2 \mathrm{C}$ & $30-40$ & 28.7 & No & None & 37.7 & $\begin{array}{c}\text { Light } \\
\text { productive } \\
\text { cough, } \\
\text { diarrhoea } \\
\end{array}$ & NA & NA & NA & Recovery \\
\hline \multirow[t]{2}{*}{ Cluster 3} & Case $3 \mathrm{~A}$ & $60-70$ & 19.7 & No & None & $\begin{array}{l}37.6- \\
38.5\end{array}$ & Chills & NA & $4 \cdot 4$ & $\begin{array}{l}\text { Two patchy } \\
\text { ground glass } \\
\text { opacity high- } \\
\text { density shadows } \\
\text { in right lung }\end{array}$ & Death \\
\hline & Case 3B & $80-90$ & 19.8 & No & $\begin{array}{l}\text { Hypertension, } \\
\text { cardiac } \\
\text { disease, COPD }\end{array}$ & 38.2 & $\begin{array}{l}\text { Poor } \\
\text { appetite, } \\
\text { dry cough }\end{array}$ & $\begin{array}{l}\text { Influenza } \\
\text { A and B } \\
\text { negative }\end{array}$ & 7.2 & $\begin{array}{c}\text { Interstitial } \\
\text { hyperplasia and } \\
\text { infection of both } \\
\text { lungs }\end{array}$ & Death \\
\hline
\end{tabular}

BMI: body mass index; COPD: chronic obstructive pulmonary disease; COVID-19: coronavirus disease; NA: not available.

received treatment on 30 January. Respiratory specimens of Cases $1 \mathrm{D}$ and $1 \mathrm{E}$ were rRT-PCR positive for SARS-CoV-2 on 1 February and 31 January, respectively (Figure 1).

All five cases of Cluster 1 wore masks during their visits to hospital. In addition to the confirmed cases, there were seven close contacts of Cluster 1 cases: Case 1A's parents and a close family member, as well as Case $1 \mathrm{~B}$ and $1 \mathrm{C}$ 's parents. The close contacts were all living together with cases in respective households. None of them had symptoms or signs compatible with COVID-19 during the 14 -day medical observation at home.

Among the five cases in Cluster 1 , Cases $1 \mathrm{~A}$ and $1 \mathrm{D}$ travelled outside of Shanghai, and Case $1 E$ lived outside Shanghai. Cases $1 \mathrm{~A}, 1 \mathrm{D}$ and $1 \mathrm{E}$ did not have contact with persons known to have fever or respiratory symptoms in the cities they had recently visited. During the wedding and family dinners, there were no participants from Hubei Province or any other areas with local sustained transmission of SARS-CoV-2 at the time. Gym X turned out to be the most probable source of infection of Cases $1 \mathrm{~A}$ and 1D. From 11 January to 19 January, five persons exercised in Gym $\mathrm{X}$ on several occasions, who were confirmed as COVID-19 cases by the local CDC in early February. This time period overlapped with the time period when Cases $1 \mathrm{~A}$ and $1 \mathrm{D}$ exercised in Gym $X$. None of the five cases in Cluster 1 had contact with other persons known to have fever or respiratory symptoms in Shanghai. Close contact between Cases $1 \mathrm{~A}, 1 \mathrm{~B}$ and $1 \mathrm{C}$ when Case $1 \mathrm{~A}$ was asymptomatic was the likely infection source for Cases $1 B$ and $1 C$.

\section{Cluster 2}

Cluster 2 involved five confirmed COVID-19 cases, three males and two females aged between 9 months and their early 6os. Cases $2 \mathrm{~A}$ and $2 \mathrm{~B}$ are parents of Case $2 \mathrm{D}$ and $2 \mathrm{C}$, respectively. Case $2 \mathrm{C}$ and $2 \mathrm{D}$ are Case 2E's (infant case) parents.

Case $2 \mathrm{~A}$ and their spouse lived in Wuhan, Hubei province. They stayed at home except for purchasing food items in market. They had not been to Wuhan's Huanan Seafood Wholesale Market or been in contact with wild animals in Wuhan. Case $2 \mathrm{~B}$ had diabetes as underlying disease. Cases $2 \mathrm{C}, 2 \mathrm{D}$ and $2 \mathrm{E}$ lived together in an apartment in Shanghai. Case $2 \mathrm{~B}$ lived together with their spouse in another apartment in Shanghai and their daily activities were purchasing food items at the 


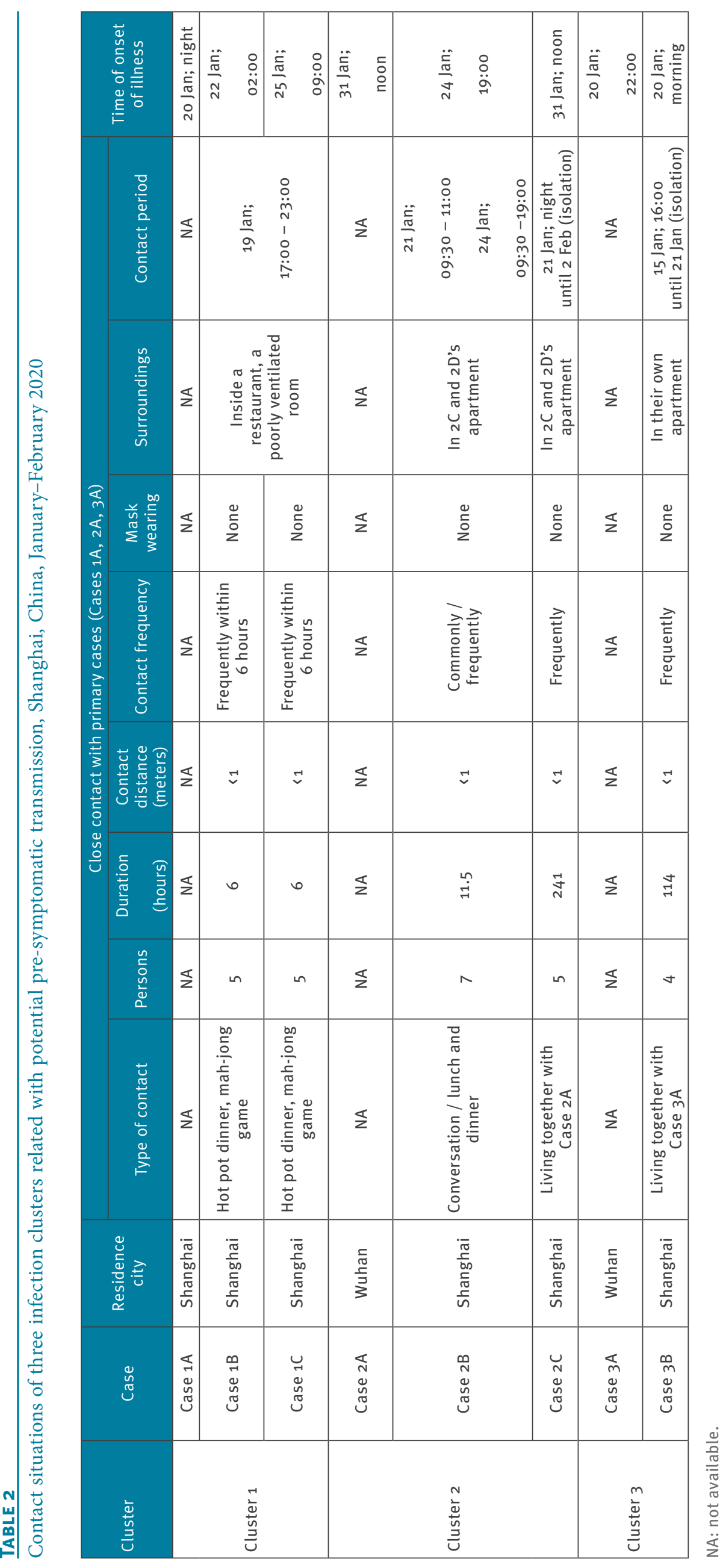


market and cooking in Case $2 \mathrm{C}$ and 2D's home. They had lunch and dinner with the young family and went back to their own home every day. Case $2 \mathrm{C}$ commuted to and from work regularly. Case $2 \mathrm{D}$ took care of Case $2 \mathrm{E}$ at home.

Case $2 \mathrm{~A}$ and spouse drove from Wuhan to Shanghai on the morning of 21 January and lived in Case $2 \mathrm{C}$ and 2D's apartment since then. Case $2 \mathrm{~B}$ and their spouse arrived in Case 2 C's apartment soon afterwards. Case $2 \mathrm{~B}$ went back home after having a conversation with Case 2A and their spouse for ca 1.5 hours. Case $2 \mathrm{~A}$, their spouse, Case 2B's spouse and Case $2 \mathrm{D}$ talked to each other, had lunch and had dinner together until evening. Case $2 \mathrm{C}$ joined dinner after work in the evening. Case 2B's spouse went back home that evening. On 22 January and 23 January, Case $2 B$ and their spouse stayed at their own apartment. At 09:30 on 24 January, Case $2 \mathrm{~B}$ and their spouse arrived in Case $2 \mathrm{C}$ and 2D's apartment. The seven persons stayed together, had lunch and dinner, celebrating the spring festival until almost 19:00 that evening. Case $2 B$ and their spouse went back home that evening. After 24 January, Case $2 \mathrm{~B}$ and their spouse stayed at their own apartment and did not go outside. After 24 January, Case $2 \mathrm{~A}$ and their spouse, Cases $2 \mathrm{C}, 2 \mathrm{D}$ and $2 \mathrm{E}$ stayed at Cases $2 \mathrm{C}$ and 2D's apartment and did not go outside.

Case 2A developed cough around noon of 31 January. As Case 2B's close contact with symptoms, they presented to hospital, were suspected as COVID-19 case, and were admitted to hospital for isolation and treatment on 2 February. The nasopharyngeal swab was rRT-PCR positive for SARS-CoV-2 on 3 February.

Case $2 \mathrm{~B}$ developed fever $\left(38.0^{\circ} \mathrm{C}\right)$ at 19:00 at their own home on 24 January. They presented to hospital on 25 January and 30 January, twice, wearing mask, accompanied by their spouse. Because Case $2 \mathrm{~B}$ had fever, they visited hospital again, accompanied by their spouse, were suspected as COVID-19 case, and were admitted to hospital for isolation and treatment on 1 February. The examination showed: body temperature was $37.3^{\circ} \mathrm{C}$, white blood cell count was $3.9 \times 10^{9} / \mathrm{L}$. Chest CT scan showed infectious lesions of the upper lobe of both lungs and thin nodular shadow of the upper lobe of the left lung. The nasopharyngeal swab was rRT-PCR positive for SARS-CoV-2 on 2 February.

Case $2 \mathrm{C}$ became symptomatic with a light productive cough and diarrhoea around noon of 31 January, 1 hour after illness onset of Case 2A. As Case 2B's close contact with symptoms, they presented to hospital, were suspected as COVID-19 case, were isolated and received treatment on 2 February. The nasopharyngealthroat swabs were rRT-PCR negative for SARS-CoV-2 on 3 February and positive on 4 February.

As Case 2B's close contacts, Cases 2A and 2B's spouses, as well as Cases $2 \mathrm{D}$ and $2 \mathrm{E}$ had been asymptomatic and were admitted to hospital on 2 February. The nasopharyngeal swabs of cases $2 \mathrm{D}$ and $2 \mathrm{E}$ were both rRT-PCR positive for SARS-CoV-2 on 3 February. The nasopharyngeal swabs of Cases 2A and 2B's spouses were both twice rRT-PCR negative for SARSCoV-2 at an interval of 24 hours (Figure 2).

Except for confirmed cases and Cases 2A and 2B's spouses, there were no other close contacts of Cluster 2.

Among the five cases in Cluster 2, only Case $2 \mathrm{~A}$ had a history of living in Wuhan. Cases $2 \mathrm{~B}, 2 \mathrm{C}, 2 \mathrm{D}$ and $2 \mathrm{E}$ had not travelled outside Shanghai. In Shanghai, none of these five cases had known contact with other persons with fever or respiratory symptoms and other persons coming from Hubei Province or any other areas where local sustained transmission of SARS-CoV-2 existed. Before Case 2B's onset of symptoms, Case 2B went to a market and Case $2 \mathrm{C}$ went to work regularly. Considering the COVID-19 situation in Shanghai and Wuhan at that time, close contact with pre-symptomatic Case $2 \mathrm{~A}$ was the most likely infection source of Cases $2 B$ and $2 C$. The likelihood of Cases 2B and 2C's exposure to other sources in Shanghai was considered much lower.

\section{Cluster 3}

Cluster 3 involved four confirmed COVID-19 cases, two males and two females, aged between 60 and 80 years. Case $3 \mathrm{~A}$ is Case $3 \mathrm{D}$ 's spouse. Case $3 \mathrm{C}$ is Case $3 B$ 's spouse. Case $3 A$ and Case $3 C$ are siblings.

Cases 3A and 3D lived in Wuhan, Hubei Province. They stayed at home except for purchasing food items in the market. They had not been to Wuhan's Huanan Seafood Wholesale Market or been in contact with wild animals in Wuhan. Cases $3 B$ and $3 C$ lived in Shanghai. Case $3 B$ was a long-term bedridden patient with several comorbidities (hypertension, cardiac disease and chronic obstructive pulmonary disease). Case 3 C purchased food items, cooked meals and took care of Case $3 \mathrm{~B}$ at home.

Cases 3A and 3D arrived in Shanghai by train on 15 January and stayed in Case 3B and 3C's apartment since 16:00 that day. On 16 January and 17 January, Cases $3 \mathrm{~A}, 3 \mathrm{C}$ and $3 \mathrm{D}$ went shopping at a nearby supermarket twice. Apart from this, the four cases stayed at home and did not go outside.

Case $3 \mathrm{~A}$ became symptomatic with chills and fever at 22:00 on 20 January. They presented to hospital, were suspected as COVID-19 case, and were admitted to hospital for isolation and treatment on 21 January. The examination showed: body temperature was $38.5^{\circ} \mathrm{C}$, white blood cell count was $4.37 \times 10^{9} / \mathrm{L}$. Chest CT scan showed two patchy ground glass opacity high-density shadows in the right lung. The throat swab was rRT-PCR positive for SARS-CoV-2 on 22 January. Case 3 A died in hospital in March.

Case 3B developed poor appetite and dry cough on the morning of 20 January and fever $\left(38.2^{\circ} \mathrm{C}\right)$ on 21 
January. They presented to hospital, were suspected as COVID-19 case, and admitted to hospital for isolation and treatment on 21 January. The examination showed: white blood cell count was $7.16 \times 10^{9} / \mathrm{L}$. Influenza $A$ and $B$ antigen tests were both negative. Chest CT scan showed interstitial hyperplasia and infection of both lungs. The nasopharyngeal swab and throat swab were both rRT-PCR positive for SARS-CoV-2 on 22 January. Case $3 \mathrm{~B}$ died in hospital on 25 January.

As close contact of Cases $3 \mathrm{~A}$ and $3 \mathrm{~B}$, Case $3 \mathrm{C}$ developed fever $\left(38.2^{\circ} \mathrm{C}\right)$; Case $3 \mathrm{D}$ also developed fever $\left(37.4^{\circ} \mathrm{C}\right)$, both at 09:00 on 23 January, and they were both admitted to hospital on the same day. The nasopharyngeal swabs and sputum specimens of Cases $3 \mathrm{C}$ and $3 \mathrm{D}$ were both $\mathrm{rRT}-\mathrm{PCR}$ positive for SARS-CoV-2 on 24 January (Figure 3 ).

Except for confirmed cases, there were three close contacts of Cluster 3 cases, including Case $3 B$ and $3 C$ 's child, their spouse and grandchild, who had visited Case 3B. They did not have any symptoms or signs during the 14-day medical observation at home.

Cases $3 A$ and $3 D$ had histories of living in Wuhan. Cases $3 B$ and $3 C$ had not travelled outside Shanghai. In Shanghai, none of the four cases had known contact with other persons with fever or respiratory symptoms and persons coming from Hubei Province or any other areas where local sustained transmission of COVID-19 existed. Case $3 \mathrm{~B}$ was a long-term bedridden patient. Close contact with Case $3 \mathrm{~A}$ when they were pre-symptomatic was the most likely infection source of Case 3B.

\section{Analysis of clusters}

In these three infection clusters, 14 confirmed cases developed symptoms and visited hospitals when they were in Shanghai and eight of these confirmed cases were related with potential pre-symptomatic transmission (Table 1). CDCs' public health physicians conducted field epidemiological investigations and communicated with the cases directly; contact situations of three infection clusters are shown in Table 2. In each of the clusters, the primary cases were identified (Cases 1A, 2A, 3A) and in total five cases (Case 1B, ${ }_{1} C, 2 B, 2 C, 3 B$ ) were secondary cases who got infected by being in close contact with the primary cases. The primary cases $1 \mathrm{~A}, 2 \mathrm{~A}$ and $3 \mathrm{~A}$, had no clinical symptoms or signs when they were in contact with these five secondary cases, and there were no contacts after the illness onset of the primary cases. In Cluster 1, illness onset in the five secondary cases was 2 to 5 days after the last contact with the primary case. In Cluster 2 and Cluster 3, illness onset in secondary cases occurred prior to or on the same day as the onset in the primary cases. The interval between the onset of illness in the primary case and the last contact of the secondary case with the primary case in our report was 1 to 7 days. No other relevant exposure histories of the secondary cases were found.

\section{Outbreak control measures}

Multiple control measures were implemented immediately once these three clusters were detected. First, isolation and treatment was performed immediately when patients were suspected to have COVID-19 according to doctors' judgment based on the existing guidelines [18]. Suspected cases were transferred by ambulance to a municipal-designated hospital once their respiratory specimens were rRT-PCR positive for SARS-CoV-2. Second, close contacts were put under centralised or home medical observation for 14 days since the last day of contact with cases, under supervision of a team including clinical physicians, nurses, CDC physicians, and community workers. During observation, body temperature and respiratory symptoms or signs were recorded twice every day. Third, disinfection measures were implemented in cases' homes, visited hospitals, work places and other places where cases had spent time, to prevent secondary infections. Fourth, surveillance in fever clinics and health education for the population were strengthened especially in areas where the infection clusters occurred. Fifth, people arriving to Shanghai from other provinces or foreign countries were health quarantined for 14 days in a centralised isolation location, and observed medically with body temperature and respiratory symptoms or signs being recorded twice every day.

\section{Discussion}

The study provides empirical evidence for transmission of COVID-19 in the pre-symptomatic phase. It supports the 5 th version of Prevention and Control Guidelines for Novel Coronavirus Pneumonia published by the National Health Commission of the People's Republic of China on 21 February [21] which refers to close contacts as those in close contact with cases without effective protection from 2 days before the onset of symptoms. In their research, Zou et al. showed that the viral load detected in asymptomatic COVID-19 cases was similar to that in symptomatic ones [22], which suggests the transmission potential of asymptomatic or minimally symptomatic patients.

In April 2020, WHO interim guidelines also suggested that individuals who had contact with a confirmed case from 2 days before symptom onset should be identified and traced [23]. These changes to the earlier WHO interim guidelines emphasised the importance of looking for contacts in their pre-symptomatic stage. The longest interval between the onset of illness in the primary case and the last contact of the secondary case with the primary case in our report was 7 days, which was longer than 2 days and within the ranges of published mean incubation period (5.1-11.5 days) according to recent research $[11,24,25]$. An alternative explanation could be that the initial symptoms of the primary case of Cluster 2 were too mild to self-recognise. Both explanations of this study provide clues for further research on pre-symptomatic transmission of COVID-19. 
Unlike SARS-CoV-1, where almost all onward transmissions occur after symptom onset [26], published evidence of pre-symptomatic transmission has been accumulating for SARS-CoV-2 [14-16,27,28]. Transmission before symptom onset has a marked effect on control and prevention of infectious diseases. It increases the probability for the population to get infected, and weakens the power of isolation because contacts may have got infected already before isolation of the cases [29]. In the study by Mizumoto et al., the estimated asymptomatic proportion was $17.9 \%$ (95\% credible interval: $15.5-20.2 \%$ ) [27]. The clinical spectrum and infection spectrum of COVID-19 still need to be studied deeper to help public health decision making.

Among the three infection clusters, pre-symptomatic transmission appeared to take place when (i) the exposure time was sufficiently long i.e. equal to or more than 6 hours, (ii) the exposure distance was short i.e. less than $1 \mathrm{~m}$, (iii) the exposure frequency was high and the distance was short i.e. living together in one house, dining or playing together at one table, and (iv) no masks were worn when in contact. This indicates that pre-symptomatic person-to-person transmission can happen when there is sufficient exposure with a confirmed COVID-19 case. However, we do not know whether shorter or less intense exposures to pre-symptomatic cases might also lead to transmission.

There are two main limitations that need to be acknowledged. First, the evidence case reports provide is less persuasive than results of well-designed studies where information is obtained following a specific protocol. Second, even with detailed field investigation and information that was cross-checked from multiple sources, considering recall bias, there is still chance that not every possibility for transmission was recorded, such as whether there were alternative sources for Cluster 2.

This report also showed that COVID-19 can be transmitted between families, friends and cities. Transmission has taken place all over the world $[30,31]$. Strict measures were adopted in the early stage of the COVID-19 epidemic in Shanghai, which resulted in decreasing numbers of reported confirmed and suspected cases. In the past months people have been returning to Shanghai for work from all over China and people have been arriving in Shanghai from all over the world; Shanghai is facing great challenges in preventing imported cases. Medical observation and centralised isolation of people from abroad was strengthened. Health quarantine for 14 days in centralised isolation location for every traveller returning from other countries is crucial in preventing imported COVID-19 cases, which can lead to imported cases in this pandemic. The potential pre-symptomatic person-to-person transmission puts forward higher requirements for research and prevention and control measures. Until the infectivity and duration of incubation period transmission are conclusive, more research is needed for optimising prevention and control strategies, including seroprevalence studies, natural history studies based on population in epidemic areas, and studies about efficiency of asymptomatic transmission. The incubation period should be taken into consideration in epidemiological investigations and the identification of close contacts. Moreover, the importance of pre-symptomatic transmission in outbreak evolution needs to be in far wider and deeper consideration.

\section{Acknowledgements}

The authors of this study thank all the cases and the cases' relatives, the public health physicians from Baoshan, Huangpu, Putuo, Pudong district CDCs and Shanghai municipal $C D C$, the nurses and the clinical physicians from hospitals for the strong support during the epidemiological investigations.

Funding: This work was supported by Science and Technology Commission of Shanghai Municipality (Study on the seroepidemiology and transmission risk of COVID-19, grant number 20JC1410200; Shanghai Sailing Program, grant number20YF1441700; The Epidemiological study on COVID-19 in Shanghai, grant number 20411950100).

\section{Conflict of interest}

None declared.

\section{Authors' contributions}

Xiaohuan Gong and Wenjia Xiao analysed the infection clusters, drafted the manuscript and acquired the funding. Yan Cui and Yuanping Wang participated in the manuscript revision and epidemiological investigation. Xiaohuan Gong, Wenjia Xiao, Dechuan Kong, Shenghua Mao, Yaxu Zheng, Yan Cui, Yuanping Wang, Lunhui Xiang and Lu Lu collected the information and participated in the epidemiological investigation. Chenyan Jiang, Xiao Yu, Yiyi Zhu and Qiwen Fang analysed the data. Huanyu Wu and Hao Pan conceived the study, gave valuable instruction and acquired the funding, in epidemiological investigation and in laboratory test and analysis, respectively.

\section{References}

1. The Novel Coronavirus Pneumonia Emergency Response Epidemiology Team. The epidemiological characteristics of an outbreak of 2019 novel coronavirus diseases (COVID-19) China, 2020. China CDC Weekly.2020;2(8):113-22. https://doi. org/10.46234/ccdcw2020.032

2. Wang C, Horby PW, Hayden FG, Gao GF. A novel coronavirus outbreak of global health concern. Lancet. 2020;395(10223):470-3. https://doi.org/10.1016/S01406736(20)30185-9 PMID: 31986257

3. Zhu N, Zhang D, Wang W, Li X, Yang B, Song J, et al. A novel coronavirus from patients with pneumonia in China, 2019. N Engl J Med. 2020;382(8):727-33. https://doi.org/10.1056/ NEJMoa2001017 PMID: 31978945

4. World Health Organization (WHO). Statement on the second meeting of the International Health Regulations (2005) Emergency Committee regarding the outbreak of novel coronavirus (2019-nCoV). Geneva: WHO; 30 Jan 2020. Available from: https://www.who.int/news-room/ detail/30-01-2020-statement-on-the-second-meeting-of-theinternational-health-regulations-(2005)-emergency-committeeregarding-the-outbreak-of-novel-coronavirus-(2019-ncov). 
5. World Health Organization (WHO). Director-General's opening remarks at the media briefing on COVID-19 - 11 March 2020. Geneva: WHO; 11 Mar 2020. Available from: https://www. who.int/dg/speeches/detail/who-director-general-s-openingremarks-at-the-media-briefing-on-covid-19---11-march-2020.

6. World Health Organization (WHO). Coronavirus disease 2019 (COVID-19) Situation report - 69. Geneva: WHO; 29 Mar 2020. Available from: https://www.who.int/docs/default-source/ coronaviruse/situation-reports/20200329-sitrep-69-covid-19. pdf?sfvrsn=8d662ofa_2

7. Kinross P, Suetens C, Gomes Dias J, Alexakis L, Wijermans A, Colzani E, et al. Rapidly increasing cumulative incidence of coronavirus disease (COVID-19) in the European Union/ European Economic Area and the United Kingdom, 1 January to 15 March 2020. Euro Surveill. 2020;25(11):2000285. https:// doi.org/10.2807/1560-7917.ES.2020.25.11.2000285 PMID: 32186277

8. World Health Organization (WHO). Coronavirus disease 2019 (COVID-19) Situation report - 174. Geneva: WHO; 12 July 2020. Available from: https://www.who.int/docs/default-source/ coronaviruse/situation-reports/20200712-covid-19-sitrep-174. pdf?sfvrsn=5d1c1b2c_2.

9. National Health Commission of the People's Republic of China (NHC). Epidemic situation of COVID-19 on January 22. Beijing: NHC; 22 Jan 2020. Available from: http://www.nhc.gov.cn/xcs/ yqtb/202001/a3c8b5144067417889d8760254b1a7ca.shtml

10. Shanghai Municipal Government of the People's Republic of China. Shanghai declared the first-level response for major public health emergency to firmly curb the spread of the epidemic. Shanghai: Shanghai Municipal Government of the People's Republic of China; 25 Jan 2020. Available from: http://www.shanghai.gov.cn/nw2/nw2314/nw2315/nw4411/ u21aw1423526.html

11. Li Q, Guan X, Wu P, Wang X, Zhou L, Tong Y, et al. Early transmission dynamics in Wuhan, China, of novel coronavirusinfected pneumonia. N Engl J Med. 2020;382(13):1199-207. https://doi.org/10.1056/NEJMoa2001316 PMID: 31995857

12. Chan JF, Yuan S, Kok KH, To KK, Chu H, Yang J, et al. A familial cluster of pneumonia associated with the 2019 novel coronavirus indicating person-to-person transmission: a study of a family cluster. Lancet. 2020;395(10223):514-23. https:// doi.org/10.1016/S0140-6736(20)30154-9 PMID: 31986261

13. Huang R, Xia J, Chen Y, Shan C, Wu C. A family cluster of SARSCoV-2 infection involving 11 patients in Nanjing, China. Lancet Infect Dis. 2020;20(5):534-5. https://doi.org/10.1016/S14733099(20)30147-X PMID: 32119823

14. Nicastri E, D’Abramo A, Faggioni G, De Santis R, Mariano A, Lepore L, et al. Coronavirus disease (COVID-19) in a paucisymptomatic patient: epidemiological and clinical challenge in settings with limited community transmission, Italy, February 2020. Euro Surveill. 2020;25(11):2000230. https://doi.org/10.2807/1560-7917.ES.2020.25.11.2000230 PMID: 32209164

15. Rothe C, Schunk M, Sothmann P, Bretzel G, Froeschl G, Wallrauch C, et al. Transmission of 2019-nCoV infection from an asymptomatic contact in Germany. N Engl J Med. 2020;382(10):970-1. https://doi.org/10.1056/NEJMc2001468 PMID: 32003551

16. Bai Y, Yao L, Wei T, Tian F, Jin DY, Chen L, et al. Presumed asymptomatic carrier transmission of COVID-19. JAMA. 2020;323(14):1406. https://doi.org/10.1001/jama.2020.2565 PMID: 32083643

17. Li P, Fu JB, Li KF, Liu J-N, Wang H-L, Liu L-J, et al. Transmission of COVID-19 in the terminal stages of the incubation period: A familial cluster. Int J Infect Dis. 2020;96:452-3. https://doi. org/10.1016/j.ijid.2020.03.027 PMID: 32194239

18. National Health Commission of the People's Republic of China (NHC). The 3 rd version of Prevention and Control Guidelines for Novel Coronavirus Pneumonia. Beijing: NHC; 28 Jan 2020. Available from: http://www.nhc.gov.cn/jkj/s7923/202001/47ob 128513 fe 46 fo86d79667db9f76a5.shtml

19. World Health Organization (WHO). Coronavirus disease (COVID-19) technical guidance: Laboratory testing for 2019-nCoV in humans. Geneva: WHO. [Accessed: 2 Apr 2020]. Available from: https://www.who.int/emergencies/ diseases/novel-coronavirus-2019/technical-guidance/ laboratory-guidance

20. The Standing Committee of the National People's Congress of the People's Republic of China (NPCSC). Law of the People's Republic of China on prevention and control of infectious diseases. Beijing: NPCSC; 30 Aug 2018. Available from: http:// www.nhc.gov.cn/fzs/s3576/201808/6dooc158844f42c5bcf949 93bffa665a.shtml

21. National Health Commission of the People's Republic of China (NHC). The $5^{\text {th }}$ version of prevention and control guidelines for novel coronavirus pneumonia. Beijing: NHC; 21 Feb 2020.
Available from: http://www.nhc.gov.cn/jkj/s3577/202002/ a5d6f7b8c48c451c87dba14889b30147.shtml

22. Zou L, Ruan F, Huang M, Liang L, Huang H, Hong $Z$, et al. SARSCoV-2 viral load in upper respiratory specimens of infected patients. N Engl J Med. 2020;382(12):1177-9. https://doi. org/10.1056/NEJMc2001737 PMID: 32074444

23. World Health Organization (WHO). Interim guidance: Considerations in the investigation of cases and clusters of COVID-19. Geneva: WHO; 2 Apr 2020. Available from: https:// www.who.int/publications-detail/considerations-in-theinvestigation-of-cases-and-clusters-of-covid-19

24. Backer JA, Klinkenberg D, Wallinga J. Incubation period of 2019 novel coronavirus (2019-nCoV) infections among travellers from Wuhan, China, 20-28 January 2020. Euro Surveill. 2020;25(5):2000062. https://doi.org/10.2807/1560-7917. ES.2020.25.5.2000062 PMID: 32046819

25. Lauer SA, Grantz KH, Bi Q, Jones FK, Zheng Q, Meredith $\mathrm{HR}$, et al. The Incubation Period of Coronavirus Disease 2019 (COVID-19) From Publicly Reported Confirmed Cases: Estimation and Application. Ann Intern Med. 2020;172(9):57782. https://doi.org/10.7326/M20-0504 PMID: 32150748

26. Glasser JW, Hupert N, McCauley MM, Hatchett R. Modeling and public health emergency responses: lessons from SARS. Epidemics. 2011;3(1):32-7. https://doi.org/10.1016/j. epidem.2011.01.001 PMID: 21420657

27. Mizumoto K, Kagaya K, Zarebski A, Chowell G. Estimating the asymptomatic proportion of coronavirus disease 2019 (COVID-19) cases on board the Diamond Princess cruise ship, Yokohama, Japan, 2020. Euro Surveill. 2020;25(10):2000180. https://doi.org/10.2807/1560-7917.ES.2020.25.10.2000180 PMID: 32183930

28. Wang Y, Liu Y, Liu L, Wang X, Luo N, Li L. Clinical outcomes in 55 patients with severe acute respiratory syndrome coronavirus 2 who were asymptomatic at hospital admission in Shenzhen, China. J Infect Dis. 2020;221(11):1770-4. https:// doi.org/10.1093/infdis/jiaa119 PMID: 32179910

29. Hellewell J, Abbott S, Gimma A, Bosse NI, Jarvis CI, Russell TW, et al. Feasibility of controlling COVID-19 outbreaks by isolation of cases and contacts. Lancet Glob Health. 2020;8(4):e48896. https://doi.org/10.1016/S2214-109X(20)30074-7 PMID: 32119825

30. Okada P, Buathong R, Phuygun S, Thanadachakul T, Parnmen S, Wongboot W, et al. Early transmission patterns of coronavirus disease 2019 (COVID-19) in travellers from Wuhan to Thailand, January 2020. Euro Surveill. 2020;25(8):2000097. https://doi.org/10.2807/1560-7917.ES.2020.25.8.2000097 PMID: 32127124

31. Holshue ML, DeBolt C, Lindquist S, Lofy KH, Wiesman J, Bruce $\mathrm{H}$, et al. First case of 2019 novel coronavirus in the United States. N Engl J Med. 2020;382(10):929-36. https://doi. org/10.1056/NEJMoa2001191 PMID: 32004427

\section{License, supplementary material and copyright}

This is an open-access article distributed under the terms of the Creative Commons Attribution (CC BY 4.0) Licence. You may share and adapt the material, but must give appropriate credit to the source, provide a link to the licence and indicate if changes were made.

Any supplementary material referenced in the article can be found in the online version.

This article is copyright of the authors or their affiliated institutions, 2020. 